\title{
Cultivate Innovate Personnel and Promote the Renaissance of Science and Technology with Chinese Education Wisdom
}

\author{
Sha Ouyang ${ }^{1}$, Jie Lin $^{2}$ \\ ${ }^{1}$ Hunan University of Commerce, Changsha, 410205, China \\ ${ }^{2}$ Hangzhou Normal University Qianjiang College, Hangzhou, 310018, China
}

\begin{abstract}
This article realizes from history that the achievements of ancient Chinese science and technology benefited from the unification and strength of the country, the open-minded, the fully inclusiveness, the rationality, the practice and so on. Today, China has made brilliant achievements in the past 40 years of reform and opening-up. In order to become one of the world's main scientific center and innovation highland, higher education should better inherit and develop the Chinese education wisdom of "Teaching without Discrimination", "Teaching in Accordance with Natural Aptitude", "the Unity of Knowledge and Action", "All-round in Literature and Science"... to help the Chinese nation's Road of scientific and technological rejuvenation.
\end{abstract}

Keywords: higher education; innovate personnel training; China's ideas and measures

\section{Introduction}

Minister of Education, Chen Baosheng spoke at the National Conference on Undergraduate Education in Colleges and Universities in the New Era., "First of all, China should become a powerful country in higher education and cultivation of innovative talents if China want to become a powerful country and the world's major scientific center and innovation highland." This points out that higher education should take cultivating innovative talents as the task of the times. British scholar Tempel once said, "More than half of the world's important inventions and creations originate from China". We try to pursue the Chinese education wisdom from the environment of ancient China's science and technology achievements, and use it for reference to develop our teaching work to cultivate innovate personnel.

\section{Science and Technology in Ancient China Once Led the World Trend}

When ancient Egypt was unified as a slave state, China had not yet entered the Xia Dynasty. Ancient Egypt had mastered copper-making technology and began to build pyramids. When the Babylonians created advanced mathematics and astronomy, China was in the Shang Dynasty. When China entered the Zhou Dynasty, ancient Greece entered the Homer era. Ancient Greek mathematician and philosopher, Pythagoras proposed the Pythagorean Law when China was in the Spring and Autumn Period, and Buddhism was founded by Sakyamuni in ancient India. During the Warring States Period of China, Aristotle, an ancient Greek philosopher, invented formal logic such as syllogism $\cdots$ But Pre-Qin China's 
relevant achievements have also attracted worldwide attention (We summarize the achievements of each dynasty in Table 1). "Yin and Yang" is the foundation of ancient Chinese philosophy, and is one of the important achievements of ancient Chinese natural science too. The Mohist has scientific methods and many inventions and creations. The Taoism has "Tao begets all things"; The Confucianism has "heaven and earth are constant"; The Logicians has ancient Chinese logic... The various schools of thought profound and broad in the contention, and firmly laid the root of the Chinese nation's ideology and culture. The prosperity of the Han Dynasty was due to the contention of a hundred schools of thought until the Emperor Yuan of Han really sole respect for Confucianism. "Confucianism flourished and government declined, while obedience and harmony and highly respected in society, the Han Dynasty declined after the Emperor Yuan and the Emperor Cheng".

Table 1. Summary of relevant achievements in ancient China

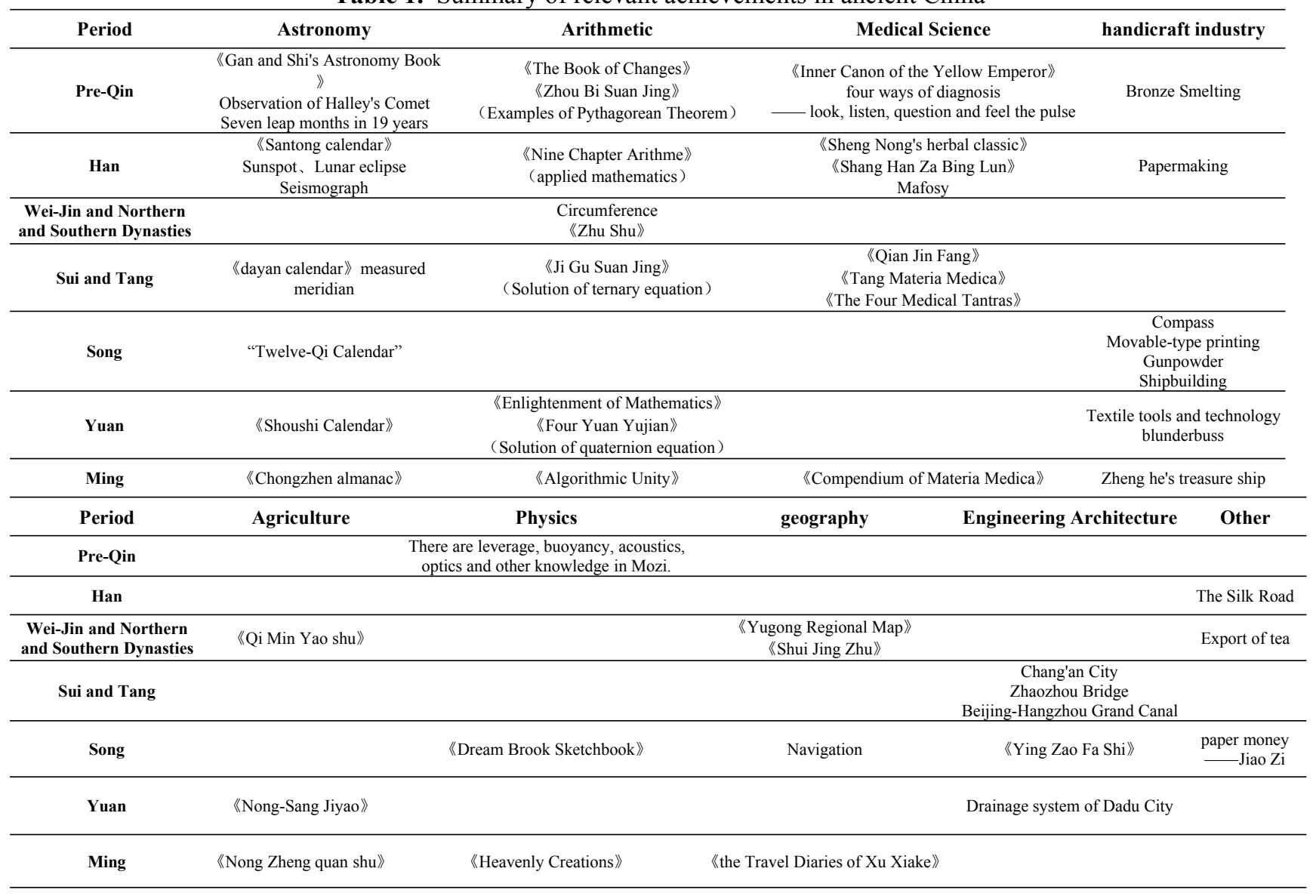

The turbulence of society promotes the increasing rationality of society after the Han Dynasty was divided into three parts. In Wei-Jin period, the people advocate Metaphysics. Literature and art were especially popular. Learning was purely for personal cultivation. Family education was flourishing. Specialty education of local official education began to appear. There were special educations for Arithmetic and the imperial doctor in the Northern Wei Dynasty. In the Northern Zhou Dynasty, there were special educations for Arithmetic too. There were also special educations for guqin, game of go, calligraphy, painting, shooting and other "All kinds of skills". Cao Cao broke through the traditional personnel standards, adhered to the principle of meritocracy and eclectic talent. Emperor Wu of Liang created an era of learning for the poor. Emperor $\mathrm{Wu}$ of Chen enabled the poor to enter the political stage. Agricultural talents for farming, craftsmen who teach people how to make tools, business talents for helping the country make money are all talents.

During the Southern Dynasty, Buddhism began to prevail in China. Cultural integration began to emerge. In addition, 
"The prosperity of schools in the early Sui Dynasty is the peak since the Wei Dynasty. The short fluctuation, in the late Sui Dynasty, did not hurt the fundamentals. So, in the early Tang Dynasty, talents came forth in large numbers". During the Taizong period of Tang Dynasty, the system of practical education and overseas students were established. The ideological trend of multiple integration and blooming flowers is strongly guaranteed by the system after the country was reunited. The Tang Dynasty ushered in the flourishing age of Wude, Zhenguan and Kaiyuan. The great spirit of inclusiveness and unprecedented innovative vitality lead the world trend for hundreds of years.

After the Song Dynasty unified the Central Plains again, the scientific and technological achievements of ancient China reached another peak. Three of the four great inventions of ancient China belong to the Song Dynasty. The reason is that lecturing freely was restored and education focused on self-study, self-understanding and free discussion in the Song Dynasty. Xining School, chaired by Wang Anshi, and Chongning School, chaired by Cai Jing, resumed the special educations for medicine, martial arts, law, arithmetic, calligraphy and painting. The most important thing is that New Confucianism restored the rational spirit. "From Ouyang Xiu, the people in Song Dynasty had the precious spirit of doubting ancient." Zhang Zai established the system of New Confucianism. New Confucianism paid attention to on the Policy Argumentation of Jing Yi, and explored the mind, nature and world. But New Confucianism excluded Taoism, Buddhism, literature and art, more innovation but less integration. At the same time, the shackles of New Confucianism began to prevail, making the creativity of the Chinese nation to pursue and explore new knowledge and new technology increasingly weaken. When the Renaissance opened the prelude of modern European history, China was at the end of the Southern Song Dynasty.

The Yuan Dynasty of China, as a super empire with developed military forces, converge wealth into the capital. "Travels of Marco Polo" inspire a stronger desire of Europeans for Eastern civilization and wealth. China's shipbuilding and navigation reached a peak in the Ming Dynasty, and the technical content of Zheng He's treasure ships was incomparable at that time. But the Ming Dynasty began to close the country, imposed a sea ban on the Southeast coast and strengthened the Great Wall in the North. The west, on the other hand, had made great achievements in geographical discovery by using shipbuilding and navigation technology.

In fact, enlightenment thought, human nature theory, active education and so on also appeared in the mid-Ming Dynasty. Especially "Yangming's mind study", emphasizes individuality and rationality, learns widely from others' strong points, and obtains conscience in practice. However, Zhang Juzheng's reform in Wanli period made the Ming Dynasty once prosperous, but it ordered to demolish private schools and academies everywhere, which severely suppressed the rise of progressive thoughts about anti-feudal ethics, individuality liberation and spirit freedom. Although the Jesuits introduced the new scientific and technologic knowledge from the West, the changes of the world, the progress of the times, the development of science and technology, and even the innovation of finance had not attract enough attention of the Chinese people, nor did they participate in it. But prohibition and destruction of all possible progress bring to China backwardness and suffer beating.

\section{Inheriting China's Educational Wisdom and Promoting the Cultivation of Innovative} Talents

It is not difficult to find that the scientific and technological achievements of ancient China benefited first from the unity of the country, and peaceful and prosperous. Since ancient times, China has been a vast connected farming land. By unifying script, currency and measuring system, people can exchange ideas, learn from each other good production experience. The country can concentrate people, money and goods, and carry out large-scale production and construction, and jointly resist various natural disasters. Many scientific and technological achievements have also been achieved. The 
completion of the Beijing-Hangzhou Grand Canal in six years is inseparable from the guarantee and support of the whole country. At the same time, the scientific and technological achievements of ancient China benefited from the contention of hundreds of schools of thought, the openness and tolerance, various practices, and innovations... The development and progress of education and its system also play an important role. Everyone has a strong creative and innovative instinct. It is precisely the function of education to cultivate, guide and develop these instincts.

Today, after 40 years of hard struggle in reform and opening up, China has made remarkable achievements in socialist construction. The society is harmonious and stable, the people are happy and healthy, the comprehensive national strength is greatly improved, and international exchanges and cooperation are in-depth and extensive. In May 2018, President Xi Jinping spoke at Peking University about "the need for higher education, scientific knowledge and outstanding talents in the development of the Party and the state cause is more urgent than ever before". Higher education should strengthen the dissemination of scientific knowledge and train more rational, talented, courageous and innovative talents. "Serve the great rejuvenation of the Chinese nation". The long-standing Chinese culture has guided us in the direction.

\subsection{Make no social distinctions in teaching}

Confucius believed that education should not be confined to people with potential and cultivation value, but should be extended to all the people. "Heavenly Creations" known as the Encyclopedia of Chinese Crafts in the 17th Century, It was compiled by Song Yingxing after he failed in the imperial examination. "Make no social distinctions in Teaching" is to expand the social basis of education and the social source of talents. Higher education should guide all learners who enter university, constantly improve their cultural and scientific literacy. Science contains abundant rational value. On the basis of learning and mastering the law of things' development, students should keep in-depth understand of the forefront of professional disciplines and make breakthroughs and innovations by using scientific methods. It is possible to stimulate creative scientific discovery, scientific invention and technological innovation by basing ourselves on the whole country and giving full play to the power of the masses.

3.2Teach students in accordance with their aptitude

"The Doctrine of the Mean" mentioned, "Destiny is called nature, conforming to nature is called Tao, and practicing these is called teaching". In life, to follow human nature is Tao. to cultivate oneself and externalize others in Tao is to teach. To realize this nature, to exert it freely and to carry it into education is the high realm of cultivation. Because of unprecedented unity, stability and strength, the Tang people were confident and tolerant, and the whole society advocated personality and talent. Li Bai, who lived in the flourishing Tang Dynasty, "recites Liu jia at the age of five, watches hundreds of schools at the age of ten", and "watches all kinds of masterpieces at the age of fifteen"... His teacher, Zhao Rui, took good care of his nature, thus created his infinite imagination and extremely powerful spiritual world. Therefore, higher education should advocate personality and talent too, guide students to spend time and effort in their interests and expertise. Harvard President Eliot once said that the university will take whatever courses students want to take. Our firstclass universities can learn from it, while other colleges and universities can do whatever they can and gradually realize it with the help of MOOCs. Create and provide conditions for students' personalized learning, so as to cultivate professionals and top-notch talents in various fields.

\subsection{Coherence between arts and science}

Emperor Taizu of Song decided that the basic national policy of his successor was "emphasizing culture and suppressing military". China's "emphasizing culture" did never neglect the rational. It contained philosophy and scientific knowledge. Learning scientific knowledge can comprehensively understand and accumulate human wisdom. Learning philosophy can train and cultivate dialectical and rational thinking at the highest level of thinking, and meticulous thinking 
activities can help to acquire new scientific cognition, logical judgment and systematic thinking. Therefore, higher education should pay equal attention to both culture and science. First, improve science and philosophy related courses, especially the high-level courses of philosophy, which can help to perfect creative personality and creative thinking. At the same time, literature and art, creation and appreciation are effective means to cultivate people's intuitive thinking and perception. Liang Qichao once said, "The style of study in the pre-Qing Dynasty is quite similar to that in the European Renaissance. One of the most different points is that art and literature are underdeveloped". Therefore, literature and art related courses need to be complete, providing a broad space for the full development of individual imagination and free galloping, and giving inventions and creations the wings to soar.

\subsection{Unity of knowing and doing}

Ancient China's scientific and technological achievements belong to the form of agricultural civilization. Human society is in a period of development in which population is the productive force and land is the wealth. With the development of society, economy and science and technology, the generation of social wealth is no longer directly proportional to the size of the population, the area of cultivated land, the individual soldier's bravery, etc. The western modern industrial revolution and its subsequent production scale and production modernization laid a direct practical foundation for invention, creation and innovation. This profound industrial social background was not found in China at that time. Today, China has caught up with the pace of world development. And the scientific and technological revolution has entered a new era of competition involving information technology, space theory, life science, new energy, new materials, etc. We have a new practical background of using intelligence to promote the development of productive forces. Therefore, colleges and universities should provide the environment and create opportunities as far as possible, actively guide all teachers and students to devote themselves to high-level research projects and school-enterprise cooperation projects in the field of new science and technology. Know but not do, just unknown! Only by combining knowledge and practice, and only by learning, accumulating, growing and innovating in practice, can their talents be brought into full play and they can stand up in the competition of science and technology.

\subsection{The spirit of independence and the thought of freedom}

Higher education should actively advocate the study and research's independent thinking ability and independent free will, and cultivate more spirit of challenging academic authority for students. At the same time, Higher education should create a free and relaxed academic environment on campus, so that different ideas and views can be freely exchanged, unique understanding and insights can be fully expressed. The collision, intersection and infiltration of ideological sparks can bring breakthroughs and innovations.

\section{Conflicts of Interest}

The author declares no conflicts of interest regarding the publication of this paper.

\section{References}

[1] Chen B.S., Speech at the National Conference on Undergraduate Education in Colleges and Universities in the New Era, 2018-6-21, https://www.sohu.com/a/249428804_273375

[2] Zhuang S.Q. (2006). General (Behavioral) Creativity, Xuzhou:China University of Mining and Technology Press, 24.

[3] Wang B.Z. and Yan G.H. (2005). General History of Chinese Educational Thoughts, Changsha:Hunan Education Press, 44, 410, 426.

[4] Jiang G.J. (2004). On the Rise and Fall of Education: A Study of the Development Cycle of Education in Ancient China, East China Normal University, 53, 69, 162. 
[5] Gong Y.Z. (2004). Viewing the Way of Educational Innovation from "Li Bai Phenomenon", Peking University Education Review, 4, 104.

[6] Sun P.Q. (2009). The History of Education in China, Shanghai: East China Normal University Press, 335.

[7] Feng Y.L. (2001). History of Chinese Philosophy, Beijing: Commercial Press, 920.

[8] Wang Y.M. (2014). Biography, Beijing: Time Chinese Document Building.

[9] Xi J.P., Speech at the Symposium between Teachers and Students of Peking University, 2018-5-2, http://www.xinhuanet.com/2018-05/03/c_1122774230.htm

[10] Liu Z.L. (2007). Personal Evidence of Chinese Culture and Life, Wuhan: Huazhong University of Science and Technology Press, 254.

[11] Liang Q.C. (2003). An Introduction to Academic Studies in the Qing Dynasty, Tianjin: Tianjin Ancient Books Publishing House, 89. 